We believe that the doses used in the Guy's Hospital trial are, on a priori grounds, less than optimal for the destruction of residual tumour after surgery (though lethal to lymphocytes in the regional nodes). The trial has therefore compared radical surgery plus suboptimal radiotherapy with partial surgery plus suboptimal radiotherapy. The results are very much as might have been predicted, certainly so far as local recurrence is concerned.

It is regrettable that fuller use was not made of the potentialities of radical radiotherapy, the application of which would have made the conclusions of the trial more meaningful, and perhaps quite different.-We are, etc.,

E. Stanley Lee

K. A. NeWTON

Westminster Hospital

G. WESTBURY

Middlesex Hospital,
London $\$ .1$

MARgaret F. SPITtLe

1 Ellis, F., Clinical Radiology, $196920,1$.

2 Fletcher, G. H., Cancer, 1972, 29. 545. 3 Shukovksy, L. J., American fournal of Roent-
genology, 1970, 108, 27 .

\section{Chromosome Banding}

SIR,-Chromosome banding is due to the breaking of $\mathrm{H}$ bridges that link nucleotides or other compounds of the DNA. The phenomenon, called denaturation, ${ }^{1}$ has important consequences for chromosome identification, among others. Caratzali et al. ${ }^{2}$ have shown that certain tuberculostatic drugs-among which para-aminosalicylic acid (PAS)-administered in vitro in cultured human leucocytes 20 hours before harvest, give rise to numerous denatured metaphasic plates. The addition of para-aminobenzoic acid in these conditions, either alone or with PAS, also results in the production of denaturation. It is, therefore, likely that para-aminobenzoic acid $\left(\mathrm{C}_{6} \mathrm{H}_{4} \mathrm{NH}_{2} \mathrm{COOH}\right)$ and PAS $\left(\mathrm{C}_{6} \mathrm{H}_{4}\right.$ $\mathrm{NH}_{2} \mathrm{OHCOOH}$ ), competitive metabolites, should act by disturbing the normal appearance of crystalline bridges $\mathrm{H}$. At present, in my laboratory, experiments are being carried out, using another anti-metabolite of para-aminobenzoic acid, sulphanylamide.-I am, etc.,

A. Caratzali

Bucharest,
Romania

1 Rice, S. A., Doty, P, fournal of the American Chemical Society, 1957, 79, 3937.

Caratzali, A., Roman, I.-C., Cirnu-Georgian, L., Sciences. Paris, Série D., 1972, 274, 1198.

\section{Stress and the Schizophrenias}

SIR,-I read with interest your leading article "Stress and the Schizophrenias" ( 3 June, p. 550). In discussing the work done by Surgeon Captain G. G. Wallace ${ }^{1}$ you expressed surprise at the inverse ratio between severe stress and favourable outcome in the schizophrenias. However, to my mind, this relationship would seem to be a most logical one, since it is well known that, generally speaking, the more "reactive" factor in mental illness, then the better its prognosis.

This would seem to be reasonable, since if a person succumbs to mental illness only after considerable stress, then the implication is that he has a great deal of inner strength and reserve to cope with many of his life problems.-I am, etc.,

Shenley Hospital,
St. Albans, Herts Wallis, G. G., British fournal of Psychiatry,
1972, 120, 375.

\section{Aetiology of Varicosity}

SIR,-Having long since been converted to the belief that bran should be an essential part of our diet, I agree with most of what Mr. D. P. Burkitt (3 June, p. 556) says However, I find it difficult to support wholeheartedly his concept of the aetiology of varicose veins, since I believe heredity is the most important primary cause. Evidence for this is shown not only by the high familial incidence but by the tendency for the same group or groups of tributaries to be affected in successive generations. There is also the fact that veins which are not direct tributaries of either the long or the short saphenous veins frequently become varicose. Examples of this are the vein which courses over the patella and ascends on the anterolateral aspect of the thigh, vein running up the lateral aspect of the calf, and those on the posterior aspect of the thigh, which drain into the gluteal veins. It is also well known that incipient varicose veins are to be found in children around the age of 11 years. These veins then disappear during adolescence only to reappear later usually with the first pregnancy.

I suspect that the increasing incidence of varicose veins among American Negroes and New Zealand Maoris is more likely to be due to interbreeding than to a change in environment and diet. In my view the secondary causative factors, such as pregnancy, prolonged standing, increased abdominal pressure due to straining at stool, etc., will only aggravate the condition of varicose veins in those patients in whom the genetic tendency already exists but will neve cause varicosities in patients who do no possess this inherited weakness.-I am, etc.

London W.1

GORDON S. RAMSAY

SIR,-Mr. D. P. Burkitt (3 June, p. 556) is correct in stating that haemorrhoids are not rare in Southern Nigerians. Among 3,539 outpatients seen at a rural health centre in Western Nigeria 11 had symptomatic haemorrhoids. 1

Although these villagers still have largely traditional eating habits and eat food with a high fibre content, there is a common belief that haemorrhoids result from eating sugar and sweet foods. - I am, etc.,

Liverpool School of Tropical Medicine,

G. B. WyatT

University of Liverpoo

Wyatt, J. J., and Wyatt, G. B., Annals of
Tropical Medicine and Parasitology, 1967, 61,
224.

SIR,-I am not competent to comment on Mr. D. P. Burkitt's main thesis (3 June, p. 556), but may I query one of his fundamental assumptions-that piles are merely varicose veins in a particular anatomical situation. This view of piles dates from Morgagni in the 18 th century and, though contested by several authors in the 19th century, by the end of the century had acquired general acceptance and today has become almost axiomatic. Yet anyone looking at prolapsed piles, or introducing a speculum when they are present, sees what in fact piles are-exaggerated protrusions of the bowel lining at the anorectal junction. Gabriel, whom Mr. Burkitt quotes in another connexion, and Hughes $^{2}$ are the only two modern authors that I have been able to find who recognize this fact.

The uncritical acceptance of piles as varicose veins has resulted in an unnecessary narrowing down of studies on their aetiology to primary venous factors.-I am, etc.

London W.1

David Patey 1 Gabriel, W. B., The Principles and Practice of Canal and Rectum, p. 129. Edinburgh, Livingstone, 1957.

\section{Fish Cornea for Grafting}

SIR,-In this part of the world corneal opacities, vascularization, and degeneration are common and mostly bilateral, causing serious deterioration in vision. The only treatment is a corneal transplant, ${ }^{1}$ which is not possible because of the problem of obtaining human donor material. This led me to use freshly obtained fish cornea. The postoperative results have been encouraging, and I would like to report two cases of corneal opacities successfully grafted with fish cornea. In both cases the graft took with normal healing and without any postoperative complications. The lamellar graft remained clear with considerable improvement in vision while the penetrating graft became opaque later.

The first patient, a man aged 70 , had almost total corneal opacities in both eyes. There was some superficial vascularization of the left cornea and rather deep vascularization of the right cornea. Both eyes were free from active inflammation and there was no evidence of trachoma or recent infection and the corneal scars were thought to be due to reccurrent corneal ulcers in the past. The left eye was selected for the operation and a peritomy was done prior to the graft. Two weeks later a $7 \mathrm{~mm}$ lamellar corneal graft of freshly obtained fish cornea was made. The graft took: healing was normal. Two weeks after the operation the vision improved to finger counting. and he was able to recognize shapes and distinguish colours. The pupil could be seen clearly through the graft. The graft was clear when seen seven weeks after the operation.

A boy aged 4 had very dense corneal opacities in both eyes as a result of severe inflammation of both eyes when he was 2 . He had no treatment at that time as none was available in the village where he lived. Although there was some superficial vascularization of both cornea and the left eye showed early staphyloma, both eyes were in a quiet stage. No peritomy was done in this case. A $7 \mathrm{~mm}$ full-thickness graft was made Healing was uneventful. When the stiches were removed after three weeks it was found that the graft had become opaque and moderately vascularized although less so in the central part. A subconjunctival injection of cortisone was given. It was found that the child resented strong light, a sign which had not been present before operation. 